\title{
A LINGUAGEM AUDIOVISUAL EM FOCO: A EXPERIÊNCIA DO CINECLUBINHO UFTOCA
}

\author{
Arinalda Silva Locatelli ${ }^{1}$ \\ Cristiane Oliveira Rosa ${ }^{2}$
}

\begin{abstract}
RESUMO: O presente artigo busca socializar a experiência vivenciada no projeto de extensão Cineclubinho UFToca. O projeto utiliza a linguagem audiovisual como base, objetivando promover o audiovisual como um agente de desenvolvimento cultural e social para as crianças de Tocantinópolis-TO. Trata-se de um espaço rico em possibilidades para a promoção do estímulo da fantasia e do imaginário infantil, fomentando o trabalho de temas de uma forma lúdica, com vistas a contribuir para o desenvolvimento cognitivo, emocional e social da criança. Também propicia a realização de estudos, pesquisas e atividades ligadas a disciplinas dos cursos de pedagogia, que visem ampliar as possibilidades de utilização do recurso da linguagem audiovisual na atuação do(a) educador(a). Nos quatro anos de atividades do projeto, percebeu-se uma receptividade satisfatória do público, haja vista proporcionar algo novo para as crianças do município, em virtude de não haver salas de cinema e teatros na cidade. Observou-se, ainda, que o projeto contribuiu para estreitar a participação da comunidade escolar nas ações da Universidade. Assim, por meio da exibição de filmes de qualquer nacionalidade seguida de atividades lúdicas, tem-se procurado incluir as crianças tocantinopolinas no universo da Sétima Arte.
\end{abstract}

PALAVRAS-CHAVE: Educação. Audiovisual. Infância. Formação.

Audiovisual language in focus: the experience of Cineclubinho UFToca

\begin{abstract}
This article exposes what was experienced in the extension project called "Cineclubinho UFToca". It is based on the visual language, aiming to promote audiovisual materials as agents of cultural and social development of children in Tocantinópolis, Tocantins state. The project offers various possibilities to promote the stimulation of children's fantasy and imaginary, encouraging the exploration of themes in a ludic way to contribute to a cognitive, emotional and social development of the child. It also allows the accomplishment of studies, researches and activities related to the subjects of the Education Undergraduate Course, that aim to increase the possibilities for resource utilization of the audiovisual language in the performance of educator. During the four years of the project's activities, the public was satisfactory receptive, considering that the project provided new experiences to the children of the city, because they did not have movie theaters or theaters in the city. It was also noted that the project helped to strengthen the school community participation in the actions of the university. Thus, through national and international movies exhibition followed by ludic activities, it was made an attempt to include children from Tocantinópolis in the universe of the Seventh Art.
\end{abstract}

KEYWORDS: Education. Audiovisual. Children. Formation

\footnotetext{
Mestre em Educação pela Universidade Federal do Maranhão, professora no Curso de Graduação em Pedagogia da Universidade Federal de Tocantins (naldalli@uft.edu.br).

${ }^{2}$ Graduanda em Pedagogia pela Universidade Federal de Tocantins (Campus Tocantinópolis) (corosa@uft.edu.br).
} 


\section{INTRODUÇÃO}

O presente artigo busca socializar a experiência vivenciada no projeto de extensão Cineclubinho UFToca, da Universidade Federal do Tocantins (UFT), campus de Tocantinópolis, que utiliza a linguagem audiovisual como base, objetivando, primordialmente, promover o audiovisual como um agente de desenvolvimento cultural e social, atuando como estratégia no processo de educação, tornando-se um elemento de colaboração na inserção e integração social das crianças tocantinopolinas.

O Cineclubinho surgiu por causa da inquietação de uma mãe, ao ver na cidade a carência de um melhor atendimento na educação, especialmente a infantil, que, assim como no restante do país, sofre com o descompasso entre os avanços nos aspectos legais e a realidade de atendimento a este público. Pode-se mencionar o fato do município ter um déficit de $65 \%$ das crianças na faixa etária de 0 a 3 anos sem creche, segundo dados do Ministério da Educação (2012), pois as instituições existentes não atendem a demanda, o que inviabiliza concretizar o direito de todas as crianças à educação, conforme menciona a Constituição Federal de 1988 e ratifica a Declaração dos Direitos da Criança (BRASIL, 2006). Além disto, constata-se na grande maioria dos estabelecimentos de Educação Infantil e no restante da cidade a ausência de espaços de lazer, como parquinhos de diversão, livrarias, teatro e cinema. Mas, por outro lado, há um programa de extensão da universidade, conhecido como Cineclube, que realiza sessões de filmes para o público adulto, todos os sábados à tarde. Diante desse contexto, sentiu-se a necessidade de um espaço similar, todavia voltado para o público infantil, pois alguns filmes exibidos no referido projeto não eram adequados para as crianças, fazendo com que os pais não comparecessem, por não terem com quem deixar seus filhos.

Assim, foi criado o Cineclubinho UFToca, inicialmente como uma ação ligada à Brinquedoteca Mário de Andrade, outro projeto de extensão do Campus de Tocantinópolis. Mas, no ano seguinte, constitui-se um projeto autônomo, ganhando, em 2011, um espaço próprio, haja vista que, até então, a exibição de filmes acontecia no auditório do campus.

A intenção foi instituir um espaço cultural propício ao público infantil, tanto da comunidade escolar como da comunidade em geral, uma vez que, a inexistência de um cinema em Tocantinópolis impede o acesso de grande parte das crianças à formação de uma cultura midiática em outro molde que não seja só o televisivo.

Acreditamos que o Cineclubinho representa um espaço rico em possibilidades, pois conduz a promoção do estímulo da fantasia e do imaginário infantil, fomentando a ludicidade e contribuindo para o desenvolvimento cognitivo, emocional e social da criança, pois o cinema é "o campo no qual a estética, o lazer, a ideologia e os valores sociais mais amplos são sintetizados numa mesma obra de arte" (NAPOLITANO, 2005, p. 11). Além disto, consideramos que o projeto propicia a realização de estudos, pesquisas e atividades ligadas a disciplinas dos cursos de Pedagogia, que visem ampliar as possibilidades de utilização do recurso da linguagem audiovisual na atuação do(a) educador(a).

Destarte, inicialmente teceremos algumas considerações preliminares a respeito da linguagem audiovisual como um campo de formação infantil e, em seguida, apresentaremos um breve relato 
da experiência vivenciada no Cineclubinho.

\section{A linguagem audiovisual em foco}

Conforme a própria palavra já sinaliza, a linguagem audiovisual é composta pela junção dos elementos sonoros e visuais. Assim, estamos nos referindo a uma forma de comunicação direcionada a dois sentidos humanos: a visão e a audição.

Atualmente, a criança convive frequentemente com a linguagem audiovisual, por meio do cinema e, sobretudo, da televisão, seja em casa ou na escola. Entendemos que se trata de uma modalidade de comunicação que vem ganhando força no cotidiano infantil, em que a criança passa a ter contato com novos signos, códigos e valores, que podem influenciar seu desenvolvimento em diversos aspectos: estético, cognitivo, social e psicológico (FANTIN, 2007). Sob este ponto de vista não é possível ignorar as possibilidades de se utilizar esta linguagem e aqui destacamos o uso de filmes como instrumento educativo no processo de alfabetização e letramento.

Diversos estudos vêm sendo realizado sobre a relação cinema e educação e, embora não possamos dizer que há um consenso a respeito desta conexão, concordamos que:

Cinema é arte, é diversão, é indústria e, desde o final do século passado, vem encantando pessoas de todas as idades. Se mergulhar no universo do cinema é poder viver uma grande emoção, por que não aprender também? Será que o cinema é apenas diversão, sem nenhum valor educativo? (SILVA, 2007, p. 52).

Aresposta para tal questionamento indica que é possível sim utilizar o cinema como meio educativo, pois ele traz "possibilidades infinitas, no sentido de promover a contemplação de valores, a partir dos pontos de vista político, estético e ético" (SILVA, 2007, p. 53), haja vista essa linguagem carregar a perspectiva de uma aprendizagem lúdica, em que a aquisição do conhecimento para a criança pode ocorrer de uma forma prazerosa e significativa, por isso duradoura. Além disso, acreditamos que, se for bem aproveitada, essa linguagem possibilita também uma formação crítica a respeito das temáticas abordadas nos filmes, tornando possível, por exemplo, o questionamento de determinados estereótipos, ou mesmo papeis sociais. Isso porque não podemos esquecer que os filmes são produtos de uma indústria midiática e, neste sentido, carrega consigo ideologias.

Devemos considerar também que a alfabetização vem passando por várias transformações ao longo dos anos. Nesse processo de interação e de experiências, as crianças se conhecem, pensam, divergem, discutem e trocam conhecimentos e informações, isto é, "a leitura e a escrita se tornam necessárias em função do desejo de ter acesso a outras modalidades de linguagem para participar do mundo" (VYGOTSKY, 1998, p. 10). Nesse sentido, podemos afirmar que o uso do cinema no contexto de aprendizagem se traduz como uma poderosa fonte de conhecimento, cujos reflexos se dão na reconstrução da realidade, uma vez que a linguagem cinematográfica propicia a interrelação entre os filmes e o imaginário social. Neste sentido, Fresquet (2007, p. 13) pondera que, 
Nada como o cinema para sintetizar a compreensão, os sentimentos e as sensações. Na vivência do cinema enriquecemos nossa imaginação, ativamos sua capacidade combinatória, ela é afetada emocionalmente e também mobiliza emoções. A experiência do outro (cinema como um outro coletivo, diverso, múltiplo) amplifica sem par nosso horizonte, conhecimentos, ideias, sentimentos, sensações e desejos.

Partindo desta perspectiva, algumas indagações têm norteado debates em disciplinas do curso de Pedagogia (Alfabetização e Letramento; Fundamentos e Metodologia do Trabalho em Educação Infantil; Estágio na Educação Infantil) e reuniões do Grupo de Estudo sobre Linguagem, Infância e Docência (GELID). Questões como: que leitura a criança fez da história assistida e como relaciona essa história a conhecimentos já adquiridos? Que valores, temáticas, estereótipos estão presentes no filme assistido? Como a criança se relaciona com a linguagem audiovisual? Qual a postura das professoras, das escolas atendidas, durante a sessão filmica? A ludicidade esteve presente no desenvolvimento das atividades após o filme? Que importância tem o aspecto lúdico no desenvolvimento infantil? Essas são algumas das reflexões necessárias que têm sido feitas, possibilitando um novo olhar a respeito de questões como ludicidade, o conceito de alfabetização, letramento e a própria forma de se utilizar a linguagem audiovisual, tendo como base de análise a experiência vivenciada no Cineclubinho UFToca.

Assim, discutir sobre a linguagem audiovisual, tomando como perspectiva o cinema, é atender a um convite a aprender sobre nós mesmos, a tomar seriamente outras culturas, outros olhares, outros modos de pensar, sentir e ser, tendo como base, primordialmente, o que pode ser questionado, o que discordar ou colocar em evidência (FRESQUET, 2007). O projeto tem nos proporcionado buscar ativamente novas e relevantes relações entre cinema, infância e educação.

\section{Em cartaz: Cineclubinho UFTtoca}

As atividades de atendimento ao público infantil iniciaram no dia 12 de outubro de 2009, em comemoração ao dia da criança, com a exibição do filme Bolt, o super cão. A sessão ocorreu no Auditório do Campus de Tocantinópolis da (UFT) e contou com a presença de, aproximadamente, 90 crianças da comunidade local em geral, acompanhadas de seus pais.

De modo específico, o projeto busca fortalecer a integração entre comunidade escolar e comunidade acadêmica no espaço da UFT; estimular a participação da comunidade nas atividades desenvolvidas no interior da universidade, criando um espaço de atendimento às crianças que acompanham seus parentes às sessões do Cineclube; proporcionar um espaço de acesso à cultura audiovisual como uma forma de lazer e educação. Intenciona, ainda, organizar um acervo cinematográfico direcionado para o público infantil, que possa servir de subsídio pedagógico às ações docentes tanto nos projetos internos da Universidade quanto nos projetos das escolas locais.

Desde seu início, o projeto conta com a participação de discentes bolsistas do Programa Bolsa Permanência e PIBEX da UFT, responsáveis diretos pelos agendamentos das sessões e atendimento 
ao público. Estes discentes em conjunto com a coordenação elaboram, semestralmente, relatórios sobre as atividades desenvolvidas e resultados obtidos.

Embora tenha uma essência extensionista, o projeto permite o exercício interligado com as dimensões ensino e pesquisa. Este tripé concretiza-se por meio das ações: atendimento às escolas, que ocorrerem durante a semana; atendimento à comunidade local realizada aos sábados; parcerias com outros projetos da UFT, como é o caso do PIBID e disciplinas do curso de Pedagogia, como, por exemplo: Alfabetização e Letramento, Fundamentos e Metodologia do Trabalho em Educação Infantil, Educação e Tecnologia, Estágio na Educação Infantil e Anos Iniciais do Ensino Fundamental, dentre outras.

No primeiro ano de funcionamento do projeto, foi realizada uma parceria com a Secretaria Municipal de Educação de Tocantinópolis para que as escolas de Educação Infantil pudessem agendar um dia e um horário para levar suas crianças para as sessões do Cineclubinho no Campus. Para tanto, realizou-se uma reunião no início do semestre letivo com as escolas interessadas e, ao final, criou-se um cronograma definido de atendimento às turmas. A partir do segundo ano, após uma avaliação interna do resultado das primeiras ações, decidiu-se deixar o agendamento livre, ou seja, as escolas interessadas deveriam procurar os bolsistas do projeto para marcar o dia de sua sessão no momento que tivessem interesse em trabalhar com a linguagem audiovisual em sala.

A metodologia de atendimento prevê algumas etapas para sua realização compreendendo, assim, quatro momentos:

1. Reuniões para planejamento, com os integrantes do projeto no início do semestre, para a construção da programação semestral. Vale ressaltar que esta programação diz respeito aos filmes a serem exibidos aos sábados. Para as crianças das escolas locais, os filmes são escolhidos no nosso acervo pelas professoras das turmas, de acordo com o objetivo da aula.

2. Agendamento do espaço: momento em que as pessoas interessadas em utilizar o Cineclubinho são assessoradas pelas bolsistas, para discussão dos filmes a serem exibidos, levando-se em consideração a faixa etária das crianças e a temática que se deseja abordar, bem como o planejamento das atividades lúdicas a serem realizadas após o filme.

3. Exibição dos filmes: para as escolas, as professoras ou demais interessados dispõem de um dia da semana, pela manhã e a tarde, de acordo com agendamento prévio. Para a comunidade em geral, as sessões fílmicas ocorrem todos os sábados à tarde, a partir das dezoito horas.

4. Finalmente, uma vez por mês são realizadas reuniões de avaliação das atividades com a equipe executora.

O projeto sugere como atividade a ser desenvolvida após as sessões, uma conversa sobre aspectos do filme exibido, a relação com histórias infantis e outras. Depois, as crianças podem fazer desenhos, pinturas livres sobre trechos, personagens e aspectos que a criança mais se 
identificou. Todavia, temos observado que, aqui, reside um ponto frágil do projeto, pois algumas professoras que o procuram ainda possuem a concepção equivocada do uso de filmes na sala de aula como "tapa buraco" ou momento de "descanso" na sua rotina escolar. Outras querem trazer suas atividades mimeografadas prontas, sem possibilidade de alteração, ou seja, sem permitir que a criança faça interpretação e análise dos filmes a que assistiu. Estes fatos caminham em um sentido contrário à proposta inicial do projeto, que era fazer com que o docente, ao propor utilizar uma obra cinematográfica como material didático, aceitasse o desafio de atuar como um mediador entre a obra e os seus alunos. Neste sentido é que Napolitano (2005, p. 15) alerta que,

[...] A diferença é que a escola, tendo o professor como mediador, deve propor leituras mais ambiciosas além do puro lazer, fazendo a ponte entre emoção e razão de forma mais direcionada, incentivando o aluno a se tornar um espectador mais exigente e crítico, propondo relações de conteúdo/linguagem do filme com o conteúdo escolar.

Concomitante às sessões, tem-se levado os acadêmicos do curso de Pedagogia a participar de alguns momentos, no intuito de desenvolverem observações subsidiadas por discussões teóricas já realizadas em sala de aula. Além de ser foco de estudo em algumas disciplinas do curso de Pedagogia, o seu caráter interdisciplinar tem se consolidado por meio da efetivação de parcerias com outros projetos como, por exemplo, o Programa Institucional de Iniciação à Docência (PIBID). Esta parceria tem como objetivo o uso da linguagem audiovisual como recurso didático para se trabalhar habilidades de leitura. De acordo com as bolsistas do programa, o trabalho com o audiovisual revelou que

[...] é possível obter bons resultados com o uso de mídias na escola, mas para obter esses resultados é exigido do profissional todo um prévio preparo, pois as crianças têm muito domínio das mídias, porque estas fazem parte de seu quotidiano. (SANTOS et al., 2011, p. 151).

A temática também é fonte de pesquisa do Núcleo de Estudos sobre Infầncia e Linguagem (NEIL), cujo desdobramento tem sido a feitura de Trabalhos de Conclusão de Curso (TCC) por parte de alunos(as) que participam do grupo. Neste sentido, um TCC já foi defendido e mais dois estão em processo de elaboração. Vale ressaltar, que o Cineclubinho UFToca foi o primeiro projeto envolvendo exibição de filmes para crianças no âmbito da UFT.

A respeito dos atendimentos voltados para a comunidade local, o projeto iniciou timidamente, com a participação de uma ou duas crianças que vinham acompanhar seus pais às sessões do Cineclube. Atualmente, o projeto tem um público de 20 crianças, em média, como frequentadoras assíduas. Com isso, criou-se um laço de amizade entre a discente colaboradora e as crianças, que ultrapassou os muros da Universidade. O que queremos dizer com isso é que as crianças se sentem pertencentes ao mundo acadêmico.

No início elas falavam "a escola da minha mãe", "a escola da minha tia" etc. Com as sessões acontecendo todos os sábados, no horário paralelo às exibições do Cineclube, elas passaram a sentir que fazem parte deste universo e aguardam ansiosamente pela chegada do final de semana, quando é exibido um filme, e, após a sessão, sempre há uma dinâmica e algumas vezes brincadeiras do dia-a-dia, até à sessão do Cineclube se encerrar e elas voltarem para casa com seus pais. 
Para estas crianças, o espaço do Cineclubinho é mágico, porque muitas vezes seus pais não tem tempo de brincar, de conversar e nem o hábito de trazer o filme assistido na TV ou nos DVDs para a realidade ou atualidade do seu universo. No Cineclubinho, procura-se esta ligação. Consideramos importante entrar no universo das crianças, dar liberdade a elas, muitas vezes uma liberdade que não têm em casa e nem na escola. Em várias oportunidades ao passar na rua, as crianças perguntam "tia, vai ter Cineclubinho no sábado?". Mesmo no período de férias escolares a questão muito frequente é "Quando vai voltar o cineclubinho?". Conforme Silva (2007, p. 50) "[...] os cinéfilos costumam dizer que o cinema apaixona, atrai pelo que traz de abertura para a reflexão, emoção, deslumbramento e conhecimento".

As reações das crianças no espaço do Cineclubinho são fantásticas, porque é uma sala que não têm cadeiras e sim colchonetes, almofadas e uma tela projetada na parede. A maioria pergunta "Como é isso?", "Não tem televisão e como vamos assistir ao filme?". Nessa hora, explicamos como funciona essa tecnologia de passar o filme na parede; elas querem pegar as personagens dos filmes, tocando a parede com a mão ou fazendo brincadeira de sombras projetadas, essas reações são mágicas. É possível ver no rostinho dessas crianças a alegria de descobrir algo novo. Percebemos, assim, que "a alegria não chega apenas ao encontro do achado, mas faz parte do processo da busca" (FREIRE, 1996, p. 160).

Temos depoimentos de mães sobre seus filhos terem tantas novidades para contar sobre o que viram ou que brincaram. Algumas passaram a comentar que suas crianças não veem a hora de chegar o sábado, para poder participar do Cineclubinho. Recebemos um depoimento, por e-mail, de uma mãe comentando que, depois que seu filho começou a frequentar o Cineclubinho, seu desenvolvimento de comunicação com os colegas na escola mudou e ele passou a se relacionar melhor e deixar a timidez de lado.

Ao analisar, em reunião, o aumento do número de crianças e os depoimentos das mães, ficou visível para a equipe executora do projeto a importância do atendimento aos sábados como atividade de extensão. Todavia, a mesma análise também revelou a presença da dimensão da pesquisa durante o desenvolvimento desta ação. Observou-se que as experiências vividas aos sábados têm possibilitado um espaço de formação para além da sala de aula, propiciando a unidade entre teoria e prática. Ressaltamos que

[...] as dimensões da teoria e da prática são indissociáveis, já que a teoria é um conjunto de regras também práticas e que a prática não é um ato qualquer, mas um ato que concretiza um objetivo e é pensado em relação a princípios. (MICARELLO, 2005, p. 146).

Ousamos dizer que esta experiência tem prospectado um espaço de práxis para a discente colaboradora, ou seja, uma ação pensada, refletida.

Vale destacar que a partir do segundo semestre de 2011 começamos a adotar sessões todos os sábados e procuramos organizá-las por temática mensal, seguindo a mesma metodologia do Cineclube. Por exemplo, no mês de outubro de 2011, foi trabalhado o mês da criança. No último sábado do mês, a data foi comemorada com atividades lúdicas como karaokê, desenho livre, 
brincadeiras com massas de modelar caseira e pintura facial. No mês de novembro de 2011, foi discutida a temática diversidade étnico-racial, por ser o mês da Consciência Negra, para tanto foram exibidos os seguintes filmes: A princesa e o sapo, Kiriku e a feiticeira (1 e 2) e Meu malvado favorito. No ano de 2012, continuamos a trabalhar com temáticas; o número de crianças aumentou significativamente e passamos a contar com três bolsistas. Às vezes, no momento das sessões é necessário o suporte das bolsistas, da coordenação e a colaboração das mães.

Em 2011 e 2012, comemoramos o "Dia Internacional do Brincar”, que ocorre no último sábado de maio. Em média, temos a presença de trinta e cinco crianças. Ultimamente, o Cineclubinho vem apresentando mais público que o próprio Cineclube, pois muitas crianças são trazidas por seus responsáveis que não necessariamente ficam para as exibições do Cineclube, e os que ficam quase sempre trazem mais de uma criança com elas. Também temos os filhos de professores e técnicos da Universidade participando das sessões.

O aumento da participação das crianças da comunidade se reverteu, em 2013, no grande desafio do projeto, em virtude do pouco espaço para seu funcionamento. Devido ao público-alvo ser crianças de diversas faixas etárias (2a 14 anos), a responsabilidadepelaintegridade física das mesmas émuito grande.

\section{CONSIDERAÇÕES FINAIS}

Por se tratar de um projeto recente, vemos que, a princípio, seria perigoso pontuar conclusões mais específicas, visto que o processo de amadurecimento implica múltiplas tentativas de aperfeiçoamento pelo qual o Cineclubinho passará. Mas, por outro lado, sentimos a necessidade de frisar que, em se tratando de um trabalho que está em processo de construção, um dos componentes essenciais na sua constituição tem sido seus aprendizados.

As atividades realizadas até o momento têm, por um lado, ratificado a importância de projetos como esse, tanto para a comunidade interna do Campus como para a comunidade local, e isto vem se comprovando por meio dos depoimentos das crianças e de seus pais.

Podemos indicar como alguns dos resultados obtidos, primeiramente, uma maior aproximação da Universidade com a comunidade local por meio das sessões fílmicas. Durante o primeiro semestre de funcionamento (2009), foram atendidas nove escolas e 13 turmas. Em 2010, foram atendidas 11 escolas e 25 turmas de Educação Infantil. Em 2011, 10 escolas foram atendidas. O projeto participou do Dia Internacional da Animação, do Projeto Petrobrás, realizando uma Mostra de Curtas Infantis. Ao todo, o projeto já atendeu, aproximadamente, 400 crianças, tanto das escolas locais quanto da comunidade em geral.

A constituição do espaço de atendimento às crianças que acompanham seus parentes às sessões do Cineclube, fato que estabelece uma conexão entre projetos extensionistas do Campus, foi outro ganho. Um terceiro resultado diz respeito à construção paulatina de uma cultura audiovisual por parte das crianças que frequentam especialmente as sessões aos sábados, que são conduzidas por discentes ligados ao projeto. Esta cultura se observa 
por meio das atitudes das crianças durante e após as exibições fílmicas, pois se tornaram as principais divulgadoras do projeto, trazendo constantemente um novo convidado. Além disto, mostram-se atentas, observadoras de detalhes nos filmes, gostam de interpretar o que assistem e fazem isso em um clima de ludicidade, ou seja, demonstram o que aprenderam com prazer. Também, acreditamos ter inaugurado um canal de pesquisa, por meio de algumas disciplinas do curso de Pedagogia, voltado para o campo da linguagem audiovisual e sua relação com aspectos educativos como a alfabetização/letramento e o desenvolvimento infantil.

Por outro lado, vem se observando uma fragilidade do sistema educacional em relação a profissionais que tenham consciência do papel da ludicidade no processo de aprendizagem das crianças e o uso adequado da linguagem audiovisual no processo de alfabetização, tendo em vista que a discussão sobre cinema enquanto recurso pedagógico torna-se uma necessidade, haja vista que nos induz a (re) pensar sobre nós mesmos, sobre diversas culturas, outros olhares, outros modos de pensar, sentir e ser. Tendo como base, primordialmente, o que é questionado, o que se discorda ou se coloca em evidência, nos proporcionando buscar ativamente novas e relevantes relações entre cinema, infância e educação.

Temos percebido que o uso do cinema em sala de aula é uma questão ainda complexa nas escolas atuais. Na maioria das vezes, ele é visto como uma estratégia de ocupar o tempo ocioso ou deixar as crianças entretidas, o que a nosso ver é uma interpretação equivocada (observada na prática docente). Entretanto, a experiência vivida aos sábados tem fortalecido nossa perspectiva de que a telona e a sala escura deveriam funcionar como uma preciosa estratégia pedagógica para a discussão de temáticas fundamentais para a formação cognitiva, social e afetiva das crianças.

O cinema aproxima as crianças das diversas linguagens tanto específicas como artísticas, além de auxiliar os(as) professores(as) nas suas aulas, enriquecendo a forma metodológica de abordagem dos assuntos. O filme pode ser usado para discutir diversas temáticas como: linguagem oral e escrita, meio ambiente, diversidade, valores como solidariedade, respeito mútuo e muito mais, como por exemplo, a obra cinematográfica A princesa e o sapo, em que, pela primeira vez, a representação de uma princesa discutiu questões étnicas.

Nesta perspectiva, podemos afirmar que a realização deste projeto tem nos permitido refletir sobre a importância de se ter clareza do como, para que e por que utilizar determinada obra cinematográfica, possibilitando-nos o questionamento de determinados estereótipos ou mesmo papéis sociais. Tais práticas, a nosso ver, implicam o desenvolvimento das mais diversas habilidades e atitudes essenciais na formação do sujeito. 


\section{REFERÊNCIAS}

FANTIN, M. Mídia-educação e cinema na escola. Revista Teias, Rio de Janeiro, Ano 8, n. 1516, jan./dez. 2007. Disponível em: <http://www.periodicos.proped.pro.br/index.php/revistateias/ article/view/174>. Acesso em: out. 2012.

FREIRE, P. Pedagogia da autonomia: saberes necessários a prática educativa. São Paulo: Paz e Terra, 1996.

FRESQUET, A. Cinema, infância e educação. In: REUNIÃO ANUAL DA ANPED. 30., 2007, Caxambú, 2007. Disponível em: < http://www.anped.org.br/reunioes/30ra/>. Acesso em: ago. 2010 .

BRASIL. Ministério da Educação. Pro-infância: mapa da expansão das creches. Disponível em: $<$ http://painel.mec.gov.br/painel/mapas/mapaProInfancia/creche/creche/2012_2014 . Acesso em: abr. 2012.

MICARELLO, H. Formação de profissionais da educação infantil: "sair da teoria e entrar na prática"? In: KRAMER, Sônia (Org.). Profissionais de educação infantil: gestão e formação. São Paulo: Ática, 2005.

NAPOLITANO, M. Como usar o cinema na sala de aula. 2 ed. São Paulo: Contexto, 2005.

SANTOS, A. C. et al. O audiovisual como recurso didático: a experiência do PIBID de Tocantinópolis-TO. In: ARTIOLI, C. L.; ALMEIDA, J. S. de; LIMA, V. de A. (Org.). Contribuições do PIBID/UFT para a docência. Goiânia: Editora da PUC Goiás, 2011.

SILVA, R. P. Cinema e educação. São Paulo: Cortez, 2007.

VYGOTSKY, L.S. Pensamento e linguagem. 2 ed. São Paulo: Martins Fontes, 1998.

Submetido em 27 de janeiro de 2013

Aprovado em 27 de junho de 2013. 